\title{
Age is not a limiting factor for brachytherapy for carcinoma of the node negative oral tongue in patients aged eighty or older
}

Hideya Yamazaki ${ }^{*}$, Ken Yoshida ${ }^{2}$, Tadayuki Kotsuma ${ }^{3}$, Yasuo Yoshioka $^{3}$, Masahiko Koizumi $^{3}$, Souhei Furukawa ${ }^{4}$, Naoya Kakimoto ${ }^{4}$, Kimishige Shimizutani ${ }^{3}$, Tsunehiko Nishimura ${ }^{1}$

\begin{abstract}
Background: To examine the role of brachytherapy for aged patients 80 or more in the trend of rapidly increasing number.

Methods: We examined the outcomes for elderly patients with node negative oral tongue cancer (T1-3NOMO) treated with brachytherapy. The 21 patients $(2 \mathrm{~T} 1,14 \mathrm{~T} 2$, and $5 \mathrm{~T} 3$ cases) ranged in age from 80 to 89 years (median 81), and their cancer was pathologically confirmed. All patients underwent definitive radiation therapy, with low dose rate (LDR) Ra-226 brachytherapy ( $n=4$; median 70Gy), with Ir-192 ( $n=12$; 70Gy), with Au-198 $(n=1)$ or with high dose rate (HDR) Ir-192 brachytherapy ( $n=4 ; 60$ Gy). Eight patients also underwent external radiotherapy (median $30 \mathrm{~Gy}$ ). The period of observation ranged from 13 months to 14 years (median 2.5 years). We selected 226 population matched younger counterpart from our medical chart.

Results: Definitive radiation therapy was completed for all 21 patients (100\%), and acute grade 2-3 mucositis related to the therapy was tolerable. Local control (initial complete response) was attained in 19 of 21 patients (90\%). The 2-year and 5-year local control rates were 91\%, (100\% for T1, $83 \%$ for T2 and $80 \%$ for T3 tumors after 2 years). These figures was not inferior to that of younger counterpart ( $82 \%$ at 5-year, n.s.). The cause-specific survival rate was $83 \%$ and the regional control rate $84 \%$ at the 2-years follow-up. However, 12 patients died because of intercurrent diseases or senility, resulting in overall survival rates of 55\% at 2 years and $34 \%$ at 5 years.

Conclusion: Age is not a limiting factor for brachytherapy for appropriately selected elderly patients, and brachytherapy achieved good local control with acceptable morbidity.
\end{abstract}

\section{Background}

Oral tongue carcinoma is a highly curable cancer when treated with radiation therapy, especially interstitial brachytherapy [1]. Iridium-192 (Ir-192) hairpins or cesium137(Cs-137) needles are usually used for low-dose-rate (LDR) interstitial radiotherapy in Japan. We used a high-dose-rate (HDR) remote-controlled after-loading system, using an Ir-192 microsource, the MicroSelectron-HDR (Nucletron, Veenendaal, The Netherlands) installed in 1991. Since with this system there is no risk of radiation exposure except to the patient, HDR makes

\footnotetext{
* Correspondence: hideya10@hotmail.com

'Department of Radiology, Kyoto Prefectural University of Medicine, 465

Kajiicho Kawaramachi Hirokoji, Kamigyo-ku, Kyoto 602-8566 Japan

Full list of author information is available at the end of the article
}

it possible to treat patients in a normal ward, so that the quality of life during treatment may be better. We have already reported on the outcome of HDR brachytherapy for early oral tongue cancer which included a prospective Phase III study [2-4]. In addition, we reported that the efficacy of brachytherapy for T3 oral tongue cancer, especially when using HDR, was enhanced by its excellent dose distribution [5]. The number of elderly patients in Japan has been increasing steadily because of advances in both health and medical care and the leading cause of death among the elderly is cancer. The number of people aged 80 or over reached $7,130,000$ in Japan in 2007, which counts for more than $5 \%$ of the population. The problems involved in treating older patients with cancer are time pressing [6].

\section{C) Biomed Central}


As aging is a highly individualized process, the indication, strategy, and techniques of radiation therapy for the elderly should not be defined exclusively by chronologic landmarks [6]. We studied 2180 -year-old or older patients with oral tongue cancer treated by brachytherapy. Since to the best of our knowledge, there have been no previous reports regarding such patients, we conducted this retrospective review of the feasibility of brachytherapy for elderly patient with $\mathrm{T} 1-3 \mathrm{~N} 0$ oral tongue cancer.

\section{Methods \\ Patients}

Between 1967 and 2004, 21 patients (9 males and 12 females) with previously untreated mobile tongue cancer were treated with radiotherapy at Osaka University Hospital and Osaka National Hospital. Patients treated with radiotherapy combined with chemotherapy were excluded from the study. All tumors were histologically identified as squamous cell carcinoma. Table 1 lists patient and treatment characteristics. The patients' median age was 81 , ranging from 80 to 89 . There were $2 \mathrm{~T} 1$, $14 \mathrm{~T} 2$, and $5 \mathrm{~T} 3$ tumors (UICC TNM classification of 1987). During the study period, we also treated about 700 patients with T1-3N0 oral tongue carcinoma [4], with the elderly group accounting for $3 \%$ of all patients. The age of the 21 patients ranged from 80 to 89 years (median 81) at the start of radiation therapy, and the male-to-female ratio was 9:12. Performance status (PS) was classified as $0-1$, based on the World Health Organization classification. For this study, the clinical records of consecutive these 21 patients from our database were reviewed (Table 1). To compare the result of treatment to younger counterpart, we reviewed population adjusted (sex, T-stage, with external radiotherapy) 226 patients treated during same time period. The background comparison was shown in Table 2.

\section{Radiation therapy}

All implantation was done under local anesthesia. For patients in the LDR group, the treatment sources consisted of an Ir-192 pin for 12 patients, a Ra-226 needle for 4 and a ${ }^{198} \mathrm{Au}$ grain for one patient. Each needle was implanted with the Paterson-Parker system using a reference point $5 \mathrm{~mm}$ distant from the implant plane. The median dose and range for the LDR group treated with brachytherapy only was 70 Gy (61-84 Gy). Patients in the HDR group received a total dose of 60 Gy in ten fractions during one week at $5 \mathrm{~mm}$ distance from the radioactive source. Two fractions were administered per day. The time interval between fractions was more than 6 hours. Dose rates at the reference points for the LDR group were 0.30 to $0.8 \mathrm{~Gy} / \mathrm{h}$, and for the HDR group 1.0 to $3.4 \mathrm{~Gy} / \mathrm{min}$. Patients were followed up for at least
13 months or until their death, with a median follow-up time of 2.5 years (range: 1.3 - 14 years). Large T2 tumor or more including ulceration or thicker tumor received external irradiation. A total of 8 patients (T2: 3, T3: 5) underwent external radiotherapy using a Co-60 teletherapy unit or a linear accelerator. These patients received 2-3 Gy per fraction for a median dose of 30 Gy (30 - 50 Gy), and were treated with a single lateral field that involved the primary site and the upper jugular lymph nodes. Nutrition support was given by nasal tube feeding during brachytherapy. No patient required tracheostomy. The routine follow-up interval was 1 month for the first year, two months for the second year, and 3 6 months thereafter. We examined the outcomes in terms of local control, lymph node control, cause-specific and overall survival. Early toxicities were assessed by Common Toxicity Criteria version 3 (CTC v3). Late toxicities were counted if soft tissue (ulceration lasting 3 months or more) and/or bone (bone exposure and necrosis) reactions occurred.

\section{Statistical Analysis}

For a statistical analysis, a Student's t-test for normally distributed data and the Mann Whitney U-test for skewed data were used. The percentage was analyzed using a Chisquare test. Local control and survival data were estimated according to the Kaplan-Meier method, and were examined for significance with a logrank test. All analyses used the conventional $\mathrm{p}<0.05$ levels of significance.

\section{Results}

Local control, regional control, cause-specific and overall survival

The 2- and 5-year local control rates for the 21 elderly patients were both 91\% (Figure 1). The 2-year (5-year) local control rates for T1, T2, T3 tumors were $100 \%$ (100\%), 83\%, (83\%) and 80\% (not available), respectively (n.s.). These figures was not inferior to that of younger counterpart ( $82 \%$ at 5 -year, Figure 2 n.s.). Two patients showed local recurrence. An 83-year-old female (ID15) received external radiotherapy for lymph node metastasis found just after completion of brachytherapy, but local recurrence appeared and resulted in death. One more local failure occurred in an 80-year-old female with T2N0 oral tongue cancer (ID 19) treated with the Ir-192 source. During the first night of treatment in the RI ward, she tried to brush her teeth and pulled out the guide gutter of the Ir-192, so that the Ir-192 needles were replaced with Au-198, resulting in partial response and recurrence 4 months later. The 2-year and 5-year cause-specific survival (CSS) rates were both $83 \%$ (83\% and $78 \%$ in control group), but the respective overall survival rates were $55 \%$ and $34 \%(83 \%$ and $76 \%$ in control group). Incidence of lymph-node metastasis was 
Table 1 Characteristics and clinical background of the study population

\begin{tabular}{|c|c|c|c|c|c|c|c|c|c|c|c|c|c|c|c|c|}
\hline No. & Sex & Age & $T$ & $\begin{array}{l}\text { Longest } \\
\text { diameter }\end{array}$ & $\begin{array}{c}\text { Short } \\
\text { diameter }\end{array}$ & Thickness & $\begin{array}{l}\text { Tumor } \\
\text { type }\end{array}$ & $\begin{array}{l}\text { External } \\
\text { RT dose }\end{array}$ & $\begin{array}{l}\text { Brachytherapy } \\
\text { dose }\end{array}$ & $\begin{array}{l}\text { Radioactive } \\
\text { Source }\end{array}$ & $\begin{array}{c}\text { Initial } \\
\text { response }\end{array}$ & Survival & $\begin{array}{l}\text { Disease } \\
\text { control }\end{array}$ & Outcome & Complications & Comorbidity \\
\hline & & (year) & & $(\mathrm{mm})$ & $(\mathrm{mm})$ & $(\mathrm{mm})$ & & (Gy) & (Gy) & & & (year) & & (status) & & \\
\hline 1 & $\mathrm{~F}$ & 86 & 2 & 25 & 15 & 5 & exo & & 73 & Ir & $C R$ & 1.2 & NED & DID & & \\
\hline 2 & $\mathrm{~F}$ & 85 & 2 & 25 & 13 & 5 & sup & 30 & 60 & Ra & $C R$ & 7 & NED & DID & & \\
\hline 3 & M & 82 & 1 & 20 & 11 & 5 & sup & & 70 & Ra & $C R$ & 2 & NED & DID (senile decay) & & \\
\hline 4 & $\mathrm{~F}$ & 82 & 1 & 20 & 7 & 3 & $\begin{array}{l}\text { exo } \\
+ \text { ulc }\end{array}$ & & 65 & Ir & $C R$ & 6 & NED & DID (senile decay) & & Hypertention \\
\hline 5 & M & 82 & 2 & 35 & 23 & 15 & ins+ulc & 30 & 60 & Ir & $C R$ & 3 & NED & DID & & \\
\hline 6 & M & 82 & 2 & 25 & 12 & 10 & NA & & 68 & Ir & $C R$ & 1 & NED & Alive & & $\mathrm{TIA}$ \\
\hline 7 & $\mathrm{~F}$ & 81 & 2 & 25 & 12 & 10 & ulc & & 76 & Ir & $C R$ & 14 & $\begin{array}{l}\text { nodal } \\
\text { failure } \\
4 \mathrm{M}\end{array}$ & $\begin{array}{c}\text { Alive (salvaged by } \\
\text { surgery) }\end{array}$ & & \\
\hline 8 & $\mathrm{~F}$ & 82 & 2 & 38 & 17 & 10 & ind & & 48 & ms & $C R$ & 2.5 & NED & Alive & $\begin{array}{c}\text { Ulcer and bone } \\
\text { exposure after } \\
\text { biopsy }\end{array}$ & \\
\hline 9 & M & 81 & 2 & 24 & 15 & 12 & ind & & 60 & Ir & $C R$ & 1.4 & $\begin{array}{l}\text { nodal } \\
\text { failure } \\
8 \mathrm{M}\end{array}$ & $\begin{array}{l}\text { Dead (nodal } \\
\text { failure) }\end{array}$ & & \\
\hline 10 & $\mathrm{~F}$ & 80 & 2 & 23 & 7 & 5 & ind & & 70 & Ir & $C R$ & 12 & NED & DID (senile decay) & & Hypertention \\
\hline 11 & M & 80 & 2 & 23 & 18 & 7 & exo & & 75 & Ir & $C R$ & 6 & NED & Alive & & Hypertention \\
\hline 12 & M & 80 & 2 & NA & NA & NA & NA & & 70 & Ir & $C R$ & 2 & NED & DID & & \\
\hline 13 & M & 80 & 3 & 42 & 25 & 25 & ulc & 33 & 60 & ms & $C R$ & 1.4 & NED & DID & & \\
\hline 14 & M & 80 & 3 & 42 & 23 & 13 & ulc+ind & 30 & 85 & Ra & $C R$ & 3 & NED & DID (senile decay) & & \\
\hline 15 & $\mathrm{~F}$ & 83 & 3 & 42 & 20 & 20 & ulc+ind & 30 & 70 & Ra & PR & 1 & $\begin{array}{l}\text { nodal } \\
\text { failure } \\
\text { OM }\end{array}$ & $\begin{array}{l}\text { Dead (nodal } \\
\text { failure and local } \\
\text { failure) }\end{array}$ & & \\
\hline 16 & $\mathrm{~F}$ & 89 & 3 & 50 & 30 & 20 & ulc+ind & 36 & 32 & $\mathrm{~ms}$ & $C R$ & 1.3 & NED & DID & & \\
\hline 17 & $\mathrm{~F}$ & 83 & 2 & 31 & 24 & 8 & $\begin{array}{l}\text { ind } \\
\text { +exo }\end{array}$ & & 70 & Ir & $C R$ & 4 & NED & DID & & \\
\hline 18 & M & 81 & 3 & 35 & 28 & 15 & ulctind & 36 & 54 & Ir & $C R$ & 0.9 & NED & DID & & \\
\hline 19 & $\mathrm{~F}$ & 80 & 2 & 25 & 20 & 10 & ind & & 70 & $\mathrm{Au}$ & $P R$ & 1.8 & $\begin{array}{l}\text { local } \\
\text { failure } \\
4 \mathrm{M}\end{array}$ & Dead (local failure) & & \\
\hline 20 & $\mathrm{~F}$ & 80 & 2 & 25 & 20 & 6 & ind & 50 & 54 & Ir & $C R$ & 2 & NED & Alive & & \\
\hline 21 & $\mathrm{~F}$ & 82 & 2 & 27 & 22 & 12 & exo & & 54 & ms & $C R$ & 2 & NED & Alive & Mild ulcer, pain & \\
\hline
\end{tabular}

Ir; Ir-192, Ra; Ra-226, ms; Ir-192 microSelectron-HDR, Au; Au-198 grain

sup; superficial type, exo;exophytic type, ind; indurative type, ulc; ulcerative type

DID; died for intercurrent disease, DT; death for tonque cancer, NED; no evidence of disease, NA; not avairalble

TIA; transient ischemic attack 
Table 2 Background of aged patients and younger conterpart

\begin{tabular}{|c|c|c|c|c|c|c|c|}
\hline & & & & $\begin{array}{c}\text { Aged (80-) } \\
(\mathrm{N}=21)\end{array}$ & & $\begin{array}{c}\text { Control (-79) } \\
(\mathrm{N}=226)\end{array}$ & \\
\hline Age & Age & Median (Range) & & $81(80-89)$ & & $56(18-79)$ & \\
\hline \multirow[t]{2}{*}{ Gender } & Male & & & 9 & $(43 \%)$ & 101 & $(45 \%)$ \\
\hline & Female & & & 12 & $(57 \%)$ & 125 & $(55 \%)$ \\
\hline \multirow[t]{6}{*}{ T classification } & $\mathrm{T} 1$ & & & 2 & $(10 \%)$ & 30 & $(13 \%)$ \\
\hline & $\mathrm{T} 2$ & & & 14 & $(67 \%)$ & 146 & $(65 \%)$ \\
\hline & T3 & & & 5 & $(24 \%)$ & 50 & $(22 \%)$ \\
\hline & Long diameter & $(\mathrm{mm})$ & & $30 \pm 8$ & & $26 \pm 9$ & \\
\hline & Short diameter & $(\mathrm{mm})$ & & $18 \pm 7$ & & $18 \pm 8$ & \\
\hline & Thickness & $(\mathrm{mm})$ & & $11 \pm 6$ & & $9 \pm 6$ & \\
\hline \multirow[t]{4}{*}{ Source } & Ra-226 & & & 4 & $(19 \%)$ & 72 & $(32 \%)$ \\
\hline & $\mid r-192$ & & & 12 & $(71 \%)$ & 120 & $(63 \%)$ \\
\hline & $\mathrm{Au}-198$ & & & 1 & $(5 \%)$ & 0 & $(0 \%)$ \\
\hline & MS-HDR & & & 4 & $(19 \%)$ & 34 & $(15 \%)$ \\
\hline \multirow[t]{2}{*}{ External radiotherapy } & Brachytherapy only & & & 13 & $(80 \%)$ & 165 & $(73 \%)$ \\
\hline & Combined with external & adiotherapy & & 8 & $(20 \%)$ & 61 & $(27 \%)$ \\
\hline \multirow[t]{3}{*}{ Prescribed dose } & Brachytherapy & Median (Range)(Gy) & LDR & $70(54-85)$ & & $70(50-112)$ & \\
\hline & & & HDR & $54(32-60)$ & & $60(42-60)$ & \\
\hline & External radiotherapy & Median (Range)(Gy) & & LDR & & $30(12-60)$ & \\
\hline
\end{tabular}

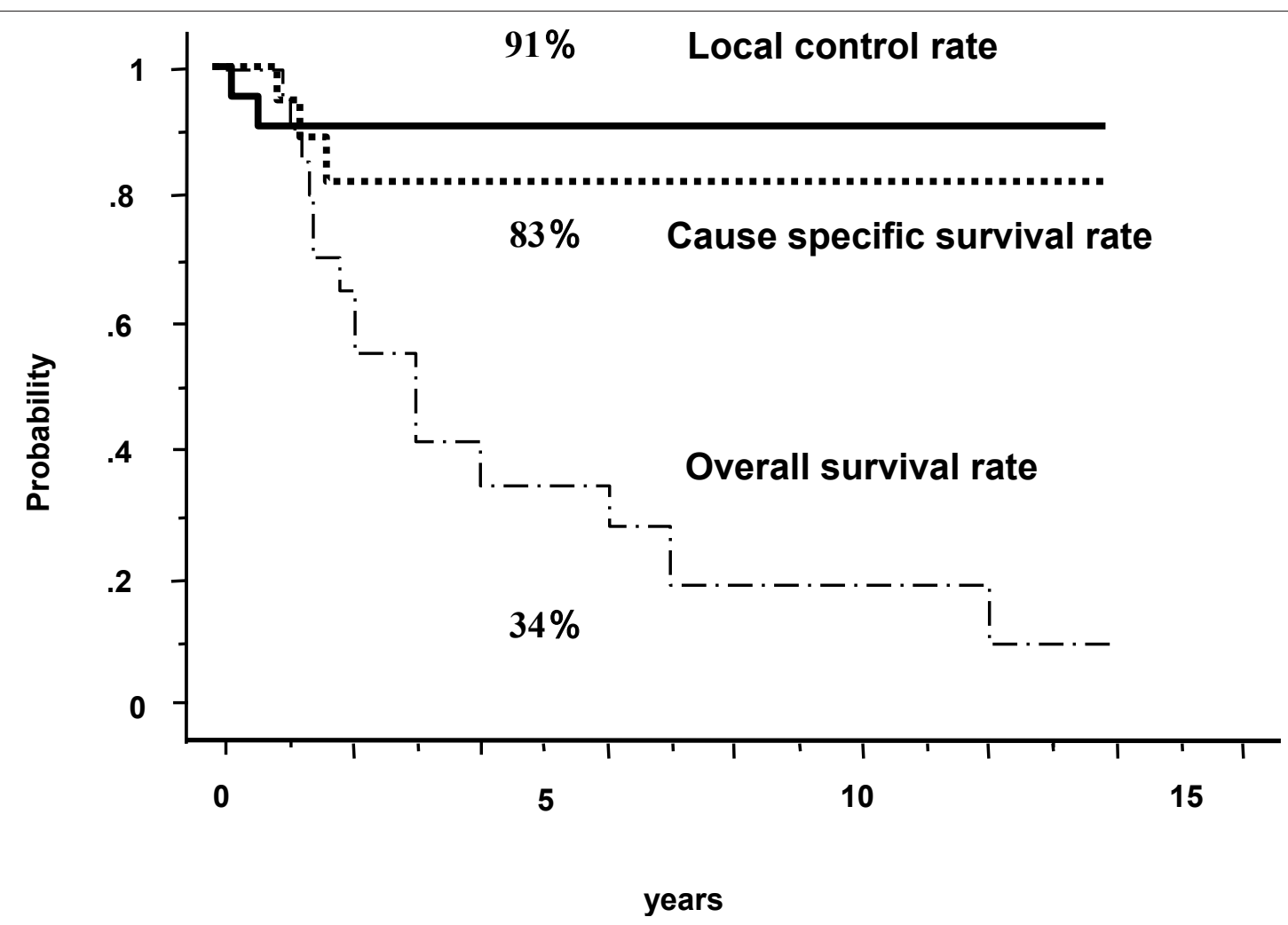

Figure $\mathbf{1}$ Local control, cause specific survival and overall survival rates for patients $\mathbf{8 0}$ or more with oral tongue cancer treated with interstitial radiotherapy. solid line; local control rate, dotted line; cause specific survival rate, dashed line; overall survival rate. 


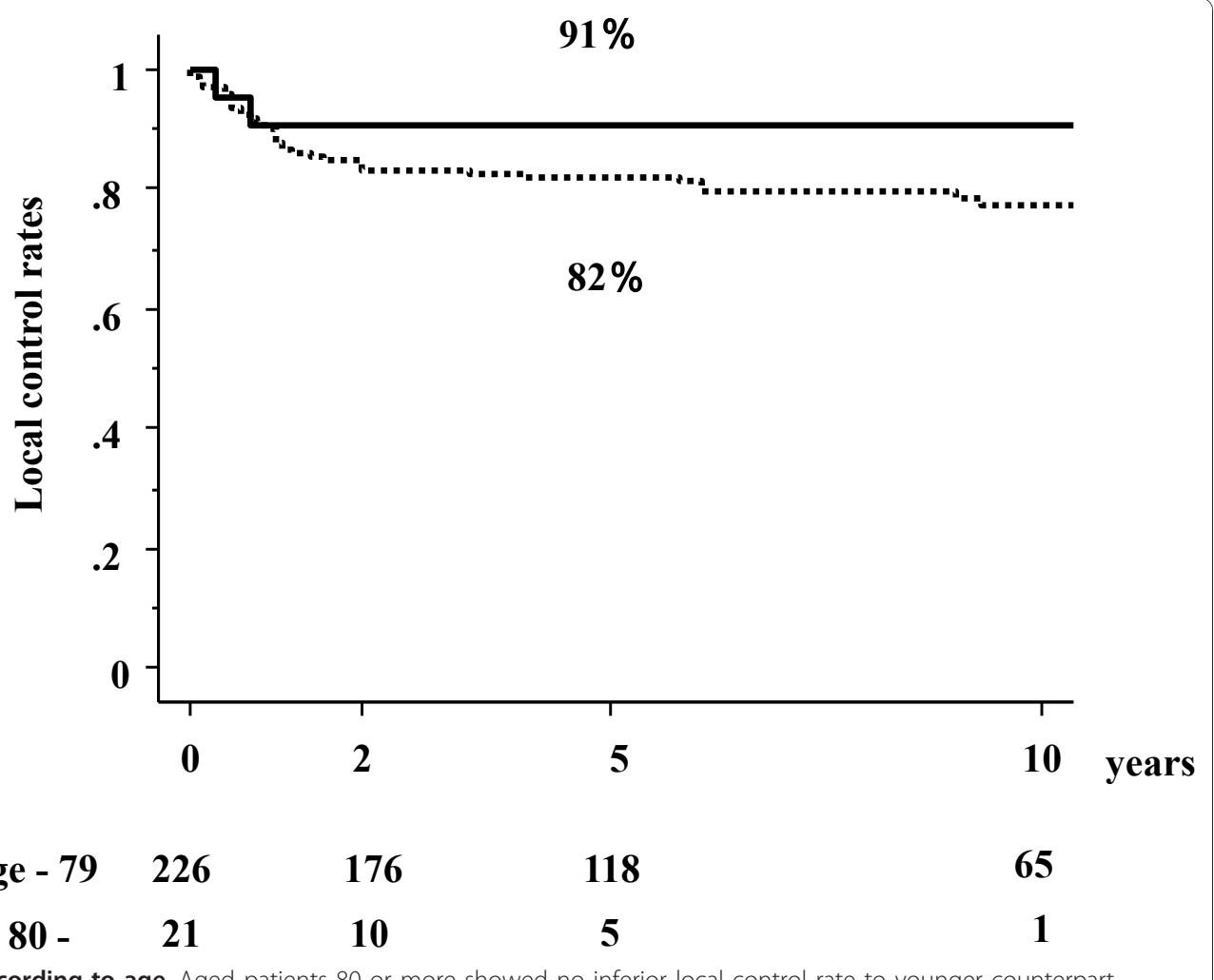

Figure $\mathbf{2}$ Local control rates according to age. Aged patients 80 or more showed no inferior local control rate to younger counterpart.

$21 \%$ at 2 years (34\% in control group) and all four recurerce appeared at ipsilateral side. Of the 4 patients who showed nodal failure, three underwent surgery, one of whom could be salvaged. Actuarially 12 patients died because of intercurrent disease or old age. The followup for 5 patients had to be terminated because the patients or their family requests.

\section{Tolerance and Complications}

Grade 2-3 acute mucositis, pharyngitis for combined external radiotherapy and oral mucositis for solely brachytherapy, occurred but were acceptable. No grade-4 skin or mucosal acute reactions were documented. The intensity of acute reactions in the elderly patients was almost the same as that observed in younger patients. Late reactions after brachytherapy comprised one bone exposure and/or two ulcer formations lasting 3 months more $(2 / 21=10 \%$; Table 1$)$. One case showed tongue deformation with ulceration scar. In previous cohort [4], 10 to $30 \%$ of delayed reaction was found according to treatment volume and addition of external radiotherapy. Aged patients showed similar ratio of delayed reaction.

\section{Discussion}

The patients 80 years old or older among those who were treated by brachytherapy accounted for about 3\% of our cohort. The incidence of carcinogenesis among this age group is currently unavailable, but oncologists are treating increasing numbers of elderly cancer patients, so that we should be more deeply concerned about treatment strategies for these patients. The deterioration of biological functions associated with aging leads to a diminished reserve capacity and increased vulnerability to age-related diseases and overall forces of mortality [6-8]. As the effects of aging depend on the individual, they manifest themselves with great variability and heterogeneity, thus making it extremely difficult if not impossible to determine a standard therapy for elderly patients based only on chronologic landmarks. When deciding on a personalized mode of treatment for older patients, it is important to assess each patient's quality of life and life expectancy. Prognostic factors related to the tumor (TNM stage, pathology, etc.), physical and/or psychological status (PS, etc.), and social support should be taken into account when estimating the outcome of treatment and life expectancy of elderly patients. However, the major part of prospective trials is carried out with patients younger than 70 so that little evidence regarding elderly patients is available.

Generally, local treatment is more appropriate than systemic therapy for the elderly. Standard chemotherapy, especially combination treatment, is not encouraged 
because of elderly patients' physiologically impaired functions and diminished reserve capacity of important organs [9-11]. Unsatisfactory outcomes of combination therapy have been reported [8], although better results with less toxic antineoplastic agents or reduced doses of chemotherapeutic agents especially designed for elderly patients with non-Hodgkin's lymphoma have been reported [12]. Moreover, the rates of acute adverse effects, morbidity, and mortality remain high for the elderly, so that extended radical surgery is not encouraged for the same reasons. It is important for their quality of life and life expectancy to attain local control of symptomatic primary lesions. Carefully planned radiation therapy for the elderly is expected to become increasingly important [13]. A prospective study has also reported the usefulness of radiotherapy for esophageal cancer in elderly patients [14], and found that patients with good PS could tolerate doses that administered according to a standard radiotherapy schedule [9]. Our findings agreed with this study in that the completion rate of radiotherapy and local control rate for elderly patients were not inferior to those for younger patients.

One of the limitations of this study is that its retrospective nature leads to a lack of detailed information about co-morbidity. This is important because cardiovascular and pulmonary diseases as well as diabetes and other diseases are more pronounced in elderly than younger patients. In addition, as mentioned in results, unexpected accidents will occur more frequently in elderly than younger patients. We found four cases of hypertention and a TIA records in patients' charts, however, they were able to be diagnosed as candidates for brachytherapy with local anesthesia and we noted that adverse reactions such as mucositis in HDR brachytherapy were similar for elderly patients: spotted mucositis started to appear three days after the end of brachytherapy while confluent mucositis developed and reached a peak at ten days, but disappeared by the fourth to eighth week without any major complications [2]. Fortunately, we did not encounter the aspiration pneumonia after brachytherapy in current study. Severe deterioration in QOL, such as speech disturbance, swallowing function loss, and frequent short hospital stay were also not a case enhanced than younger counterpart. Although the number of patients in this series was too small to draw definite conclusions regarding efficacy, late toxicity and tolerance, our data suggest the potential benefits of brachytherapy for elderly patients.

Because radiation therapy is considered to be a minimally invasive treatment procedure, it has the advantage of preserving the shape and functions of the tongue. Brachytherapy was historically performed with Ra-226, which involved exposure of the surrounding tissue. To minimize undesirable radiation to normal tissues, an afterloading technique using Ir-192 was implemented. This LDR brachytherapy has been widely used since and become the gold standard in brachytherapy. Many institutes have reported successful results for tongue cancer treated with LDR brachytherapy $[2,15]$. Since then, HDR brachytherapy using a remote afterloading technique has been introduced in several brachytherapy centers, including ours [2-4]. We previously reported our phase III data and a retrospective review with good results for T1-3 N0 patients to show the comparable outcome of HDR. However, retrospective reviews including ours reported that older patients aged 65 or over showed poorer local control than their younger counterparts $[3,4]$. In a 648-patient cohort, 5-year local control rates were $87 \%$ for $\mathrm{T} 1,78 \%$ for $\mathrm{T} 2$, and $68 \%$ for $\mathrm{T} 3$ in younger patients, but $72 \%$ for T1, $67 \%$ for T2, and $54 \%$ for T3 in elderly patients aged 65 or over $(\mathrm{p}<0.05)$ [4]. These findings prompted us to examine the background characteristics of older patients. We found that one possible explanation for poor local control was poor oral hygiene including dental factors in the elderly in previous study [12], which could be modified by careful intervention. In addition, in the study reported here, we found that patients aged 80 or over showed good outcome including four locally controlled HDR patients. Therefore age is not a sole factor on a local control rate by brachytherapy, other confounding factor such as tumor, oral hygiene, PS, co-morbidities have affected outcomes. Although further studies are needed to establish optimum schedules and techniques, elderly patients with good PS may tolerate brachytherapy schedules so that the advisability of definitive radiation therapy should be considered.

In conclusion, patients aged 80 or over showed results comparable to those for their younger counterparts, and an aggressive approach for appropriately selected elderly patients achieved good local control.

\section{Author details \\ ${ }^{1}$ Department of Radiology, Kyoto Prefectural University of Medicine, 465 Kajiicho Kawaramachi Hirokoji, Kamigyo-ku, Kyoto 602-8566 Japan. ${ }^{2}$ Department of Radiology, National Hospital Organization, Osaka National Hospital, Hoenzaka 2-1-14 Chuo-ku, Osaka city, Osaka 540-0006 Japan. ${ }^{3}$ Department of Radiation Oncology, Osaka University Graduate School of Medicine, Yamadaoka 2-2, Suita, 565-0871 Osaka, Japan. ${ }^{4}$ Department of Maxillo-Facial Radiology, Osaka University Graduate School of Densitry, Yamadaoka 1-8, Suita, 565-0871 Osaka, Japan.}

\section{Authors' contributions}

HY conceived of this study and drafted manuscript. KY participated in the design of this study. TK and YY participated in the statistical analysis. MK, SF, NK, KS and TN participated in its design and coordination and helped to draft the manuscript. All authors read and approved the final manuscript.

\section{Competing interests}

The authors declare that they have no competing interests. 


\section{References}

1. Mazeron JJ, Crook JM, Benck V, Marinello G, Martin M, Raynal M, Haddad E, Peynègre R, Le Bourgeois JP, Walop W: Iridium 192 implantation of T1 and $\mathrm{T} 2$ carcinomas of the mobile tongue. Int J Radiat Oncol Biol Phys 1990, 19:1369-1376.

2. Inoue T, Inoue T, Yoshida K, Yoshioka Y, Shimamoto S, Tanaka E, Yamazaki H, Shimizutani K, Teshima T, Furukawa S: Phase III trial of high vs. low dose rate interstitial radiotherapy for mobile tongue cancer. Int $\mathrm{J}$ Radiat Oncol Biol Phys 2001, 51:171-175.

3. Yamazaki $H$, Inoue $T$, Yoshida $K$, Imai A, Yoshioka $Y$, Tanaka E, Shimamoto S, Nakamura S, Inoue T, Nakamura H, Furukawa S, Shimizutani K: Influence of age on the results of brachytherapy for tongue cancer. Int J Radiat Oncol Biol Phys 2001, 49:931-936.

4. Yamazaki H, Inoue T, Yoshida K, Yoshioka Y, Furukawa S, Kakimoto N, Shimizutani K: Comparison of three major radioactive sources for brachytherapy used in the treatment of node negative T1-T3 oral tongue cancer: influence of age on outcome. Anticancer Res 2007, 27:491-497.

5. Kakimoto N, Inoue T, Inoue T, Murakami S, Furukawa S, Yoshida K Yoshioka Y, Yamazaki H, Tanaka E, Shimizutani K: Results of low- and highdose-rate interstitial brachytherapy for T3 mobile tongue cancer. Radiother Oncol 2003, 68:123-128.

6. Monfardini S, Yancik R: Cancer in the elderly: Meeting the challenge of an aging population. J Natl Cancer Inst 1993, 85:532-538.

7. Rodin MB, Mohile SG: A practical approach to geriatric assessment in oncology. J Clin Oncol 2007, 25:1936-44.

8. Sanoff HK, Bleiberg H, Goldberg RM: Managing older patients with colorectal cancer. Clin Oncol 2007, 25:1891-7.

9. Pignon $T$, Horiot JC, Bolla M, van Poppel $H$, Bartelink $H$, Roelofsen F, Pene F, Gerard A, Einhorn N, Nguyen TD, Vanglabbeke M, Scalliet P: Age is not a limiting factor for radical radiotherapy in pelvic malignancies. Radiother Oncol 1997, 42:107-120.

10. Bourhis J, Overgaard J, Audry H, Ang KK, Saunders M, Bernier J, Horiot JC, Le Maître A, Pajak TF, Poulsen MG, O'Sullivan B, Dobrowsky W, Hliniak A, Skladowski K, Hay JH, Pinto LH, Fallai C, Fu KK, Sylvester R, Pignon JP, MetaAnalysis of Radiotherapy in Carcinomas of Head and neck (MARCH) Collaborative Group: Hyperfractionated or accelerated radiotherapy in head and neck cancer: a meta-analysis. Lancet 2006, 368:843-54.

11. Pignon JP, le Maître A, Maillard E, Bourhis J, MACH-NC Collaborative Group: Meta-analysis of chemotherapy in head and neck cancer (MACH-NC): an update on 93 randomised trials and 17,346 patients. Radiother Oncol 2009, 92:4-14

12. O'Reilly SE, Connors JM, Howdle S, Hoskins P, Klasa R, Klimo P, Stuart DS: In search of an optimal regimen for elderly patients with advanced-stage diffuse largecell lymphoma: Results of a Phase II study of P/DOCE chemotherapy. J Clin Oncol 1993, 11:2250-2257.

13. Oguchi M, Ikeda H, Watanabe T, Shikama N, Ohata T, Okazaki Y, Ohata T, Okazaki Y, Kiyono K, Sone S: Experiences of 23 patients $>$ or $=90$ years of age treated with radiation therapy. Int J Radiat Oncol Biol Phys 1998, 41:407-13.

14. Kawashima M, Kagami $Y$, Toita T, Uno T, Sugiyama M, Tamura Y, Hirota S, Fuwa N, Hashimoto M, Yoshida H, Shikama N, Kataoka M, Akuta K, Sasaki K, Tamamoto T, Nemoto K, Ito H, Kato H, Yamada S, Ikeda H: Prospective trial of radiotherapy for patients 80 years of age or older with squamous cell carcinoma of the thoracic esophagus. Int J Radiat Oncol Biol Phys 2006 64:1112-21.

15. Yamazaki $H$, Inoue $T$, Yoshida $K$, Kotsuma T, Yoshioka $Y$, Koizumi M, Furukawa S, Kakimoto N, Shimizutani K, Nishimura T: Assessment of influence of smoking, drinking, leukoplakia and dental irritation on Local Control of Early Oral Tongue Carcinoma Treated with Brachytherapy: Age and Dental Factor are potential Prognostic Factors. Tumori 2009, 95:461-6.

doi:10.1186/1748-717X-5-116

Cite this article as: Yamazaki et al:: Age is not a limiting factor for brachytherapy for carcinoma of the node negative oral tongue in patients aged eighty or older. Radiation Oncology 2010 5:116.

\section{Submit your next manuscript to BioMed Central and take full advantage of:}

- Convenient online submission

- Thorough peer review

- No space constraints or color figure charges

- Immediate publication on acceptance

- Inclusion in PubMed, CAS, Scopus and Google Scholar

- Research which is freely available for redistribution

Submit your manuscript at www.biomedcentral.com/submit
C Biomed Central 